\title{
Time-Resolved Fluorometry Based Sandwich Hybridisation Assay for HLA-DQA1 Typing
}

\author{
Minna Sjöroos ${ }^{1 \#}$, Jorma Ilonen ${ }^{2}$, \\ Helena Reijonen ${ }^{2}$, Timo Lövgren ${ }^{1}$ \\ Departments of ${ }^{1}$ Biotechnology and \\ ${ }^{2}$ Virology, University of Turku, FIN-20520 \\ Turku, Finland

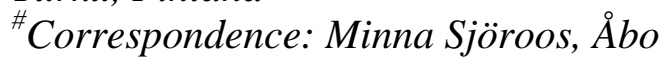 \\ Akademi University, BioCity, 3rd floor, \\ Tykistökatu 6 A, FIN-20520 Turku, Finland \\ Tel: +358 2154018; Fax: +35822154745 \\ E-mail:minna.sjoroos@utu.fi
}

\begin{abstract}
A microtitration plate based timeresolved fluorescence (TRF) hybridisation assay was developed for HLA typing utilising biotinylated sequence-specific catching probes and europium (Eu) labelled gene locus-specific detection probe to allow time-resolved fluorometer reading of the reaction. In an application for HLA-DQA typing a 228 base pair long region of the polymorphic exon 2 of DQA1 gene was amplified and the denatured PCR product distributed into streptavidin-coated microtitration wells together with the detection probe and one of the catching probes. After incubation and washes, the enhancement solution was added and specific hybridisation signal detected by measuring the emitted light. A series of 100 isolated genomic DNA samples were studied using biotinylated probes specific for DQA $1 * 01, * 0101 / 0104, * 0103 / 0201 / 0601, * 0201$, $* 03, * 0401 / 0601, * 05$ and $* 0502$ alleles with results demonstrating the capacity of the test to detect aimed alleles. A series of whole blood spot samples were also studied and the results confirmed the applicability of this modification of the test.
\end{abstract}

KEYWORDS: HLA-DQA1, hybridisation, timeresolved fluorometry
ABBREVIATIONS:
Bio biotin
EDTA ethylenediaminetetra-acetic acid

\begin{tabular}{|c|c|}
\hline $\mathrm{Eu}$ & europium \\
\hline HLA & human leukocyte antigen \\
\hline IDDM & insulin-dependent diabetes mellitus \\
\hline PCR & polymerase chain reaction \\
\hline RFLP & $\begin{array}{l}\text { restriction fragment length } \\
\text { polymorphism }\end{array}$ \\
\hline SSP & sequence-specific primer \\
\hline TRF & time-resolved fluorometry \\
\hline
\end{tabular}

\section{INTRODUCTION}

HLA typing has traditionally been performed by serological techniques. Currently, different techniques based on the identification of sequence polymorphism have become available and widely replaced the earlier methods [3]. The classical method is dot blot transfer of amplified DNA on nylon membranes followed by hybridisation with sequence-specific ${ }^{32} \mathrm{P}$ labelled oligonucleotide probes. Various modifications of the method such as reverse dot blot and replacement of radioactive isotopes by alternative labels like digoxigenin have been made. Alternatives presented later on include PCRRFLP (polymerase chain reaction restriction fragment length polymorphism) $[18,25,26]$, sequence-specific amplification [1,2,5,7,23,24] and finally direct sequencing [29] of the amplification product. The final choice of the method for HLA typing depends on several aspects such as cost of the assay (equipment and reagents required), number of samples to be screened and assay related characteristics (specificity, sensitivity, reproducibility, degree of automation etc.).

TRF $[17,31]$ is based on the use of lanthanides (europium, terbium or samarium) as labels. Lanthanide fluorescence has unique properties 
such as sharp emission peaks, large Stoke's shift (difference between excitation and emission peaks) and a fluorescence lifetime exceeding that of background fluorescence from for instance biological samples. The label is detected after a time delay, when background fluorescence has disappeared, which increases the sensitivity of the system. TRF has previously been successfully applied to many different microtitration plate based solution hybridisation assays $[6,9,10,11,13-15,16]$.

We have earlier presented an assay in which insulin-dependent diabetes mellitus (IDDM) risk related HLA-DQB1 alleles were detected using lanthanide-labelled sequence-specific probes [30]. The method was designed for screening purposes. We now describe an assay principle, in which one gene locus specific lanthanide-labelled probe is used in detection. Sequence-specific biotinylated catching probes hybridise with the amplification product and bind it into streptavidin coated microtitration plate. In this paper, the application of this assay system to HLA-DQA1 genotyping is described.

\section{MATERIALS AND METHODS}

\section{DNA samples}

To validate the developed DQA1 typing assay, one hundred isolated genomic DNA samples were tested. In addition, 14 whole blood spot samples were analysed. DNAs were extracted according to a standard phenol-chloroform procedure or a salting-out method in mini-scale [22]. Dried blood spots were prepared by pipetting $60 \mu \mathrm{l}$ of EDTA-anticoagulated (ethylenediaminetetra-acetic acid) blood onto a filter paper, followed by drying in a laminar air flow and storing at room temperature until analysed. Of the samples, 46 were controls from the 12th HLA workshop or samples typed in context of the 11th HLA workshop. DQA alleles in the rest of the samples were deduced based on the typical DRB1-DQB1-DQA1 linkages in Northern Caucasians. DQB1 and DRB1 alleles were previously characterised by ${ }^{32} \mathrm{P}$-dot-blot method [27] and sequence-specific amplification method [23], respectively.

Table 1

Primer and probe sequences with their corresponding nucleotide numbers and labels used in the HLADQA1 typing assay. The letter $\mathrm{S}$ in wo 493S and wo 609S stands for an extra spacer arm of four unspecific nucleotides in addition to the specific sequence at the $5^{\prime}$ end of the probes.

\begin{tabular}{|c|c|c|c|c|}
\hline $\begin{array}{c}\text { Oligonucleotide } \\
\text { Name }\end{array}$ & $\begin{array}{c}\text { DQA1 } \\
\text { Specificity }\end{array}$ & $\begin{array}{c}\text { Sequence } \\
\text { from 5' to 3' End }\end{array}$ & $\begin{array}{l}\text { Nucleotide } \\
\text { Numbers }\end{array}$ & $\begin{array}{l}\text { Label } \\
\text { Used }\end{array}$ \\
\hline \multicolumn{5}{|l|}{ Primers: } \\
\hline wo 484-1.U & 5 ' primer & TAT GGT GTA AAC TTG TAC CAG T & $31-52$ & none \\
\hline wo 485 & 3' primer & GGT AGC AGC GGT AGA GTT G & $240-258$ & none \\
\hline \multicolumn{5}{|l|}{ Capture probes: } \\
\hline wo $493 \mathrm{~S}$ & $* 05$ & ACC CAA TCA GAC TGT TC & $219-231$ & Biotin \\
\hline wo 494 & $* 0502$ & AAT TGC CGG TCA A & $170-182$ & Biotin \\
\hline wo $609 \mathrm{~S}$ & *0201 & CAC AGC AAC TTC CAG AC & $133-145$ & Biotin \\
\hline wo 625 & $* 0101, * 0104$ & AGA ACT CCT CAT CT & 93-106 & Biotin \\
\hline wo 632 & all alleles & AGC GTT TAA TCA & $227-238$ & Biotin \\
\hline wo 667 & $* 01$ & AAT TTG CTG AAC TC & $148-161$ & Biotin \\
\hline wo 672 & $\begin{array}{l}* 0601, * 0201, \\
* 0103\end{array}$ & TGG GTG AAC TGG & $69-80$ & Biotin \\
\hline wo 673 & $* 03$ & TCA TGG CTG TAC TG & $70-83$ & Biotin \\
\hline wo 721 & $* 0401, * 0601$ & GTT TTG TCA CAG & $200-211$ & Biotin \\
\hline $\begin{array}{c}\text { Detection probe: } \\
\text { wo } 690\end{array}$ & all alleles & CTC CAT CAA ATT CA & $81-94$ & $\mathrm{Eu}$ \\
\hline
\end{tabular}




\section{Oligonucleotides}

Primer and probe oligonucleotides are listed in Table 1 in $5^{\prime} \rightarrow 3^{\prime}$ orientation. A total number of nine biotinylated probes were used to cover the outer domain (exon 2) of the polymorphic HLADQA1 gene [20]. Most probes (Bio-493S, Bio625, Bio-667, Bio-672, Bio-673 and Bio-721) are common to several alleles whereas Bio-494 and Bio-609S are specific for one allele only. A biotinylated control probe (Bio-632) and a europium-labelled probe (Eu-690) are able to detect all alleles. For optimisation of the DQA1 assay, target sequences were used to mimic authentic DNA samples. The targets consist of an array of complementary probe sequences one after another separated by a few unspecific nucleotides. The procedures required for synthesis, labelling and purification of oligonucleotides and targets were described in detail earlier by us [30]. Briefly, oligonucleotides were synthesised using phosphoramidite chemistry and an ABI 392 DNA/RNA synthesiser. For biotinylation, one diamino-hexane-modified deoxycytidine phosphoramidite [32] was introduced into the 5' end of the capture probe during the synthesis. For the detection probe, twenty modified C's were used. Oligonucleotides were purified by polyacryl-amide gel electrophoresis using urea as a denaturing agent. Labelling of probes was carried out in a overnight reaction at room temperature using $50 \mu \mathrm{g}$ of oligonucleotide (dissolved in $1 \mathrm{mM}$ EDTA, $50 \mathrm{mM} \mathrm{Na} \mathrm{CO}_{3} \mathrm{pH}$ 9.8) and 50-fold molar excess of active biotin (SIGMA, St Louis, MO, USA) or 12-fold molar excess of active Eu chelate [12] (Wallac Oy, Turku, Finland) compared with the aminogroups introduced during the synthesis. The biotinylation reaction was purified by HPLC in a reverse-phase column (PepRPC ${ }^{\mathrm{TM}}$ HR 5/5, Pharmacia Biotech, Uppsala, Sweden). Purification of the Eu-probe was done by ethanol precipitation followed by gel filtration in a Sephadex-G50 DNA grade column (Pharmacia Biotech).

\section{PCR}

For PCR, either 100-500 ng of isolated DNA was used as a template material or PCR was run using a $3 \mathrm{~mm}$ in diameter disc of each blood spot punched directly into the PCR reagent mixture. The total volume of each reaction was $100 \mu$, consisting of $10 \mathrm{mM}$ Tris- $\mathrm{HCl} \mathrm{pH} \mathrm{8.8,} 1.5 \mathrm{mM}$ $\mathrm{MgCl}_{2}, 50 \mathrm{mM} \mathrm{KCl}, 0.1 \%$ Triton X-100 (1 x DynaZyme $^{\mathrm{TM}}$ II Buffer; Finnzymes Oy, Espoo, Finland), $0.1 \mu \mathrm{M}$ of primers, $200 \mu \mathrm{M}$ of each dNTP (Ultrapure dNTP set; Pharmacia Biotech) and $0.5 \mathrm{U}$ DNA polymerase (recombinant DynaZyme $^{\mathrm{TM}}$ II, F-501L) added in a hot-start manner. Amplification was carried out in a Perkin-Elmer DNA Thermal Cycler using the following profile: initial denaturation without DNA polymerase at $96^{\circ} \mathrm{C}$ for $5 \mathrm{~min}, 30$ repeated cycles of $45 \mathrm{~s}$ at $96^{\circ} \mathrm{C}, 45 \mathrm{~s}$ at $59^{\circ} \mathrm{C}, 1 \mathrm{~min}$ at $72^{\circ} \mathrm{C}$ and a final extension step of $5 \mathrm{~min}$ at $72^{\circ} \mathrm{C}$. A negative contamination control tube without the DNA template was included in every PCR run.

\section{Time-resolved fluorescence assay}

The principle of the assay is described in Figure 1. Briefly, $10 \mu \mathrm{l}$ of heat denatured (8 min at $96{ }^{\circ} \mathrm{C}$ in a heat block or a thermal cycler) PCR product was added in duplicate into streptavidincoated microtitration wells (Wallac Oy) together with $3 \mathrm{ng}$ of detection probe Eu-690 and $3 \mathrm{ng}$ of one out of nine biotinylated catching probes in $100 \mu \mathrm{l}$ of hybridisation solution [DELFIA ${ }^{\circledR}$ Assay Buffer; (Wallac Oy) supplemented with Tween 20 and $\mathrm{NaCl}$ to reach final concentrations of $0.1 \%$ and $1 \mathrm{M}$, respectively]. The wells were incubated at room temperature for 3 hours to form the hybrids and simultaneously collect them onto the wells. After incubation, stringent washes with DELFIA ${ }^{\circledR}$ Wash Solution were performed at $37^{\circ} \mathrm{C}$, when the biotinylated probe wo $609 \mathrm{~S}$ was used for catching the hybrids, at $35^{\circ} \mathrm{C}$ for Bio-625, at $32^{\circ} \mathrm{C}$ for Bio-672 and at $30^{\circ} \mathrm{C}$ for all other biotinylated probes. 

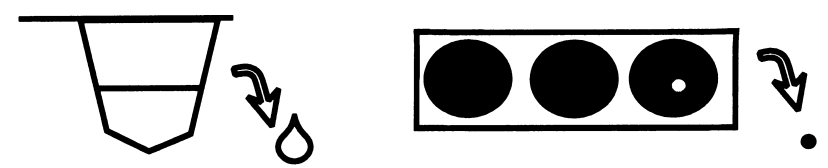

Isolated DNA or blood spot on a filter paper

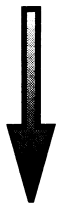

DNA amplification with primers wo 485 and wo 484-1.U
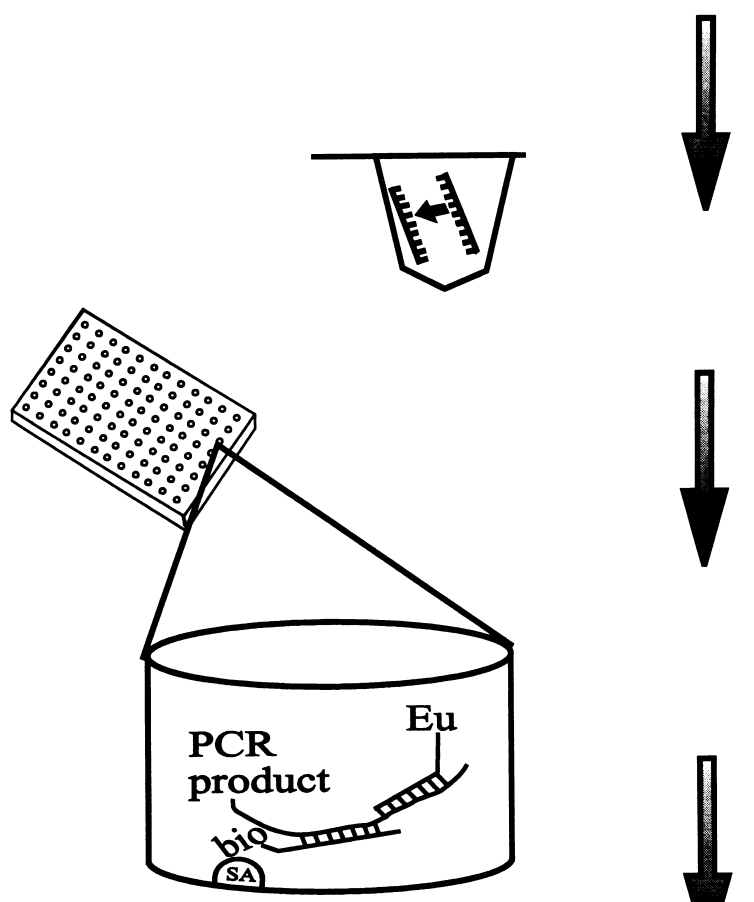

Denaturation of amplification product

Solution hybridization with a common Eu-labelled probe and a specific biotinylated probe on a streptavidin-coated plate

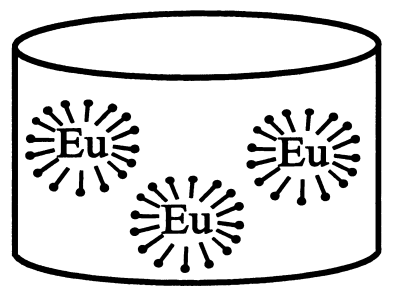

Stringent washes, addition of enhancement solution and fluorescence measurement

Fig. 1. Principle of the HLA-DQA1 assay. 
To enhance the Eu-fluorescence, $200 \mu \mathrm{l}$ of DELFIA $^{\circledR}$ Enhancement Solution was added per well and the wells were shaken at room temperature for 25 minutes. Finally, timeresolved fluorescence was detected in a 1234 DELFIA $^{\circledR}$ Research Fluorometer (Wallac Oy). The fluorometer samples each well one after another instead of sampling all 96 wells of a whole plate simultaneously, thus making the instrument more flexible for the detection of variable number of samples. Numerical results are direct readings of the fluorometer and are expressed as counts per second (cps). Often the most practical parameter to characterise hybridisation is the signal-to-noise ratio $(\mathrm{S} / \mathrm{N})$, in which signal is the specific fluorescence signal (cps) of a DNA sample and noise is the background fluorescence signal (cps) of the negative PCR control sample.

\section{RESULTS}

\section{Design of oligonucleotides}

In order to design primers capable of amplifying all DQA1 alleles, several attempts were made. The best primer set (wo 485 together with wo 484-1.U) was chosen based on obtaining both the highest possible hybridisation signal with PCR products (all different allelic DQA1 variants available) as well as the maximum band intensity of PCR products on $\mathrm{PhastGel}^{\circledR}$ Homogeneous 20 gel (Pharmacia Biotech, Uppsala, Sweden) using PhastSystem electrophoresis apparatus (Pharmacia LKB, Uppsala, Sweden).

For probes, several different sequences were also tested, especially concerning probes Bio609S, Bio-625 and Bio-672, because of their high cross-reactivity. In the case of cross-reactivity, the original probe sequence had to be shortened or a probe from another region designed. Therefore, the final probe sequences are of different lengths varying from 12 to 14 nucleotides, and thus the melting temperatures also varied from $32{ }^{\circ} \mathrm{C}$ to $42{ }^{\circ} \mathrm{C}$ according to an "A/T rule" [33].

The effect of a spacer arm of four unspecific nucleotides (denoted by $\mathrm{S}$ ) following the specific sequence at the 5' end of probes Bio-493S and Bio-609S was also tested. When comparing the probes with a spacer arm and the corresponding probes without extra nucleotides, a 2.0-fold increase on average in the specific hybridisation signal was found.

\section{PCR}

The major parameters of PCR to be optimised were found to be the concentrations of primers and $\mathrm{MgCl}_{2}$, amount of DNA polymerase added, the number of cycles and annealing temperature. In order to avoid unspecific amplification, the annealing temperature was set to $59{ }^{\circ} \mathrm{C}$. The optimum annealing temperature was determined based on the electrophoresis run of PCR products with PhastSystem. All other reaction conditions were optimised by judging the best possible S/N obtained in hybridisation with each of the probes individually. The optimal parameters chosen are mentioned above in the section Materials and Methods.

\section{Time-resolved fluorescence assay}

In our HLA-DQA1 assay, attachment of the biotinylated probe onto the well of a streptavidin plate as well as hybridisations of the biotinylated probe and Eu-labelled detection probe with the denatured PCR product were found to occur in a single step at room temperature during the threehour incubation. At this time point approximately $90 \%$ of the maximal signal (6 hours hybridisation) was reached. After hybridisation, stringent washes had to be performed to eliminate the unspecific background signal and to enhance the discrimination of probes between very homologous HLA-DQA1 alleles. Since some of the probes (Bio-609S; Bio-625; Bio-672) cross-reacted with certain alleles (DQA $1 * 03 ; * 03 ; * 05$ or $* 01$, respectively), the wash temperature had to be increased for these probes. The detailed 
washing conditions are mentioned in Materials and Methods.

The optimal probe concentration for all labelled probes used in the further assays was 3 $\mathrm{ng}$ per well $(30 \mathrm{ng} / \mathrm{ml})$. Optimisation was done separately for each of the biotinylated probes and Eu-690 in hybridisation reaction by using synthetic biotinylated targets.

The specificities of probes were tested by hybridising each of the probes one by one with PCR products derived from all possible DQA1 alleles available. A $\mathrm{S} / \mathrm{N}$ of three was chosen as the cut-off limit, i.e. ratios above three were considered positive, since no cross-reactions with "wrong alleles" were observed according to this criterion at the optimised stringent wash temperatures.

Sensitivities of probes (Table 2) were determined by using synthetic targets and based on a standard curve obtained by plotting varying amount of target molecules against the fluorescence signal (cps) obtained. The lowest detectable amount of target molecules (detection sensitivity) was defined as the value corresponding to three times the background signal. Detection sensitivities of probes were

Table 2

Hybridization sensitivities of probes determined from a standard curve as the lowest detectable amount of target molecules per well corresponding to the value of three times background signal.

\begin{tabular}{lcc}
\hline Probe & Sensitivity & $\begin{array}{c}\text { Wash } \\
\text { Temp. }\left({ }^{\circ} \mathrm{C}\right)\end{array}$ \\
\hline Bio-494 & $5.2 \times 10^{8}$ & 30 \\
Bio-632 & $1.3 \times 10^{9}$ & 30 \\
Bio-609S & $8.8 \times 10^{8}$ & 37 \\
Bio-493S & $4.3 \times 10^{8}$ & 30 \\
Bio-672 & $3.9 \times 10^{8}$ & 32 \\
Bio-673 & $6.8 \times 10^{8}$ & 30 \\
Bio-667 & $1.8 \times 10^{9}$ & 30 \\
Bio-625 & $6.8 \times 10^{8}$ & 35 \\
Bio-721 & $1.5 \times 10^{9}$ & 30 \\
Eu-690 & $4.3 \times 10^{8}$ & 30 \\
& $2.1 \times 10^{8}$ & 37 \\
\hline
\end{tabular}

found to vary from $2.1 \times 10^{8}$ molecules (Eu-690 at $37^{\circ} \mathrm{C}$ wash temperature) to $1.8 \times 10^{9}$ molecules (Bio-667).

\section{DNA samples}

Figure 2 describes the HLA-DQA1 alleles determined for 100 genomic DNA samples. Each data point represents the $\mathrm{S} / \mathrm{N}$ of one genotyped sample. The results of Bio-494 typing are not shown, since no rare $* 0502$ alleles were found and all S/N of DNA samples were below the signal-to-noise ratio of three considered as a positive reaction. On the contrary, all samples screened with the control probe Bio-632 gave a positive reaction, indicating successful DQA1 gene amplification. Because of the different lengths and wash temperatures of probes as well as differences in probe sequences, the $\mathrm{S} / \mathrm{N}$ varied significantly between probes.

Results from the DQA1 genotyping of 14 blood spots are summarised in Table 3. All samples gave a positive $\mathrm{S} / \mathrm{N}$ (cut-off value three or more) with at least two of the 9 biotinylated probes. Of the 14 blood spot samples tested, four were also genotyped using isolated genomic DNA as starting material. On average, a 1.3 6.8-fold increase in the $\mathrm{S} / \mathrm{N}$ was found when isolated DNAs were used (a 1.7-fold increase with Bio-632, 2.2-fold with Bio-667, 4.1-fold with 721, 1.7-fold with Bio-672, 6.8-fold with Bio-493S and 5.0-fold increase with Bio-625).

\section{DISCUSSION}

Determination of HLA alleles is used for several purposes. These include histocompatibility testing for transplantation, forensic medicine, anthropological studies and disease association studies aiming to estimate disease risk or reveal pathogenetic mechanisms. Each of these tasks demands increasingly different strategies as either sophisticated techniques are needed to ensure compatibility at several loci or high throughput tests are used to screen for the presence of few disease associated alleles. 
Table 3

Results from the study of 14 blood spot samples determined with the HLA-DQA1 assay. Bold numbers indicate reactions considered positive. No false typing results were obtained using the signal-to-noise ratio three as the cut-off value.

\begin{tabular}{|c|c|c|c|c|c|c|c|c|c|c|}
\hline & & \multicolumn{9}{|c|}{ Signal to Noise Ratio } \\
\hline $\begin{array}{l}\text { Blood } \\
\text { spot }\end{array}$ & $\begin{array}{l}\text { DQA1- } \\
\text { genotype }\end{array}$ & $\begin{array}{l}\text { BIO- } \\
609 S^{\text {a }}\end{array}$ & $\begin{array}{l}\mathrm{BIO}- \\
625^{\mathrm{b}}\end{array}$ & $\begin{array}{l}\text { BIO- } \\
672^{\mathrm{c}}\end{array}$ & $\begin{array}{l}\text { BIO- } \\
493 S^{d}\end{array}$ & $\begin{array}{l}\text { BIO- } \\
632^{\mathrm{e}}\end{array}$ & $\begin{array}{l}\text { BIO- } \\
667^{\mathrm{f}}\end{array}$ & $\begin{array}{l}\text { BIO- } \\
673^{\mathrm{g}}\end{array}$ & $\begin{array}{l}\text { BIO- } \\
721^{\mathrm{h}}\end{array}$ & $\begin{array}{l}\mathrm{BIO}- \\
494^{\mathrm{i}}\end{array}$ \\
\hline 1 & $* 0102, * 05$ & 0.9 & 0.7 & 1.6 & 46.7 & 63.8 & 13.9 & 1.7 & 0.8 & 0.9 \\
\hline 2 & $* 0102$ & 2.3 & 0.7 & 1.3 & 0.6 & 62.9 & 27.5 & 0.6 & 1.5 & 1.1 \\
\hline 3 & $* 0102 / 3, * 05$ & 1.8 & 0.9 & 35.7 & 41.2 & 86.2 & 15.8 & 1.9 & 0.7 & 0.9 \\
\hline 4 & $* 05$ & 0.8 & 1.2 & 2.0 & 87.3 & 81.9 & 0.5 & 0.7 & 0.7 & 0.8 \\
\hline 5 & $* 0101, * 05$ & 0.9 & 10.6 & 0.0 & 41.4 & 89.0 & 20.1 & 0.8 & 0.6 & 0.9 \\
\hline 6 & $* 0101, * 05$ & 2.0 & 9.8 & 2.2 & 35.0 & 79.0 & 19.0 & 0.8 & 1.2 & 1.0 \\
\hline 7 & $* 0102 / 3, * 03$ & 1.3 & 0.9 & 27.2 & 0.5 & 59.4 & 12.8 & 28.7 & 0.4 & 0.7 \\
\hline 8 & $* 0102, * 05$ & 1.7 & 0.4 & 1.2 & 46.3 & 33.0 & 12.4 & 1.1 & 0.6 & 0.9 \\
\hline 9 & $* 0102 / 3$ & 0.7 & 0.7 & 23.5 & 1.9 & 29.0 & 18.3 & 0.6 & 0.8 & 1.7 \\
\hline 10 & $* 0102, * 03$ & 1.6 & 1.2 & 1.2 & 0.4 & 22.2 & 6.3 & 30.4 & 0.8 & 0.6 \\
\hline 11 & $* 0101, * 05$ & 0.7 & 5.5 & 1.2 & 21.4 & 53.2 & 13.0 & 0.9 & 0.5 & 2.2 \\
\hline 12 & $* 0401, * 0102$ & 1.7 & 0.7 & 1.0 & 1.0 & 52.5 & 17.6 & 0.4 & 11.7 & 0.7 \\
\hline 13 & $* 0401, * 0102$ & 1.1 & 1.2 & 0.9 & 1.1 & 40.7 & 10.5 & 0.9 & 7.1 & 0.8 \\
\hline 14 & $* 0101 / 2$ & 1.7 & 5.3 & 0.8 & 0.7 & 42.7 & 15.4 & 1.9 & 0.8 & 1.1 \\
\hline
\end{tabular}

Allele specifities of probes: ${ }^{\mathrm{a}}=* 0201,{ }^{\mathrm{b}}=* 0101 / 0104,{ }^{\mathrm{c}}=* 0601 / 0201 / 0103,{ }^{\mathrm{d}}=* 05$,

${ }^{\mathrm{e}}=*$ common for all alleles, ${ }^{\mathrm{f}}=* 01,{ }^{\mathrm{g}}=* 03,{ }^{\mathrm{h}}=* 0401 / 0601,{ }^{\mathrm{i}}=* 0502$

The use of one lanthanide-labelled probe for detection makes the establishment of our assay cheap compared to the HLA-DQB1 screening procedure [30], where five lanthanide -labelled sequence-specific probes were used. A panel of nine biotinylated probes together with one common Eu-labelled probe are used in the HLADQA1 genotyping assay presented here. The method relies on time-resolved fluorometry detection system and a three-layer sandwich hybridisation principle (capture probe, sample DNA and detection probe) after PCR amplification of either isolated DNA or whole blood spot samples. In addition, the principle is also that of a reverse typing [4,28], with the exceptions that microtitration wells are used as solid supports instead of a membrane, and biotinylated probes do not need to be immobilised in advance, thus omitting one step. The crucial difference between our HLA-DQA1 reverse typing assay and the one very similar to ours described by Giorda et al. [8], is the detection technology. The total incubation times in the two methods are almost equal. However, in our assay 2.5 times less probes (Bio-probe and Eu-probe) are required. Moreover, after hybridisation the method of Giorda et al. is more complexed with several steps, three different wash buffers etc.

We used probe sequences of our own design instead of those mentioned in HLA workshops (for example year 1991), because with our shorter probes a better discrimination between a correctly matched and a mismatched probe can be achieved. However, our probes have been designed mainly from the same regions as the HLA workshop probes.

Our assay was tested and validated using 100 isolated DNA (Figure 2) and 14 blood spot (Table 3) samples with known/expected DQA1 genotypes. The discrimination between positive and negative samples can easily be visualised, using the $\mathrm{S} / \mathrm{N}$ of three as a cut-off value. Since no mistyping results were obtained, the assay 

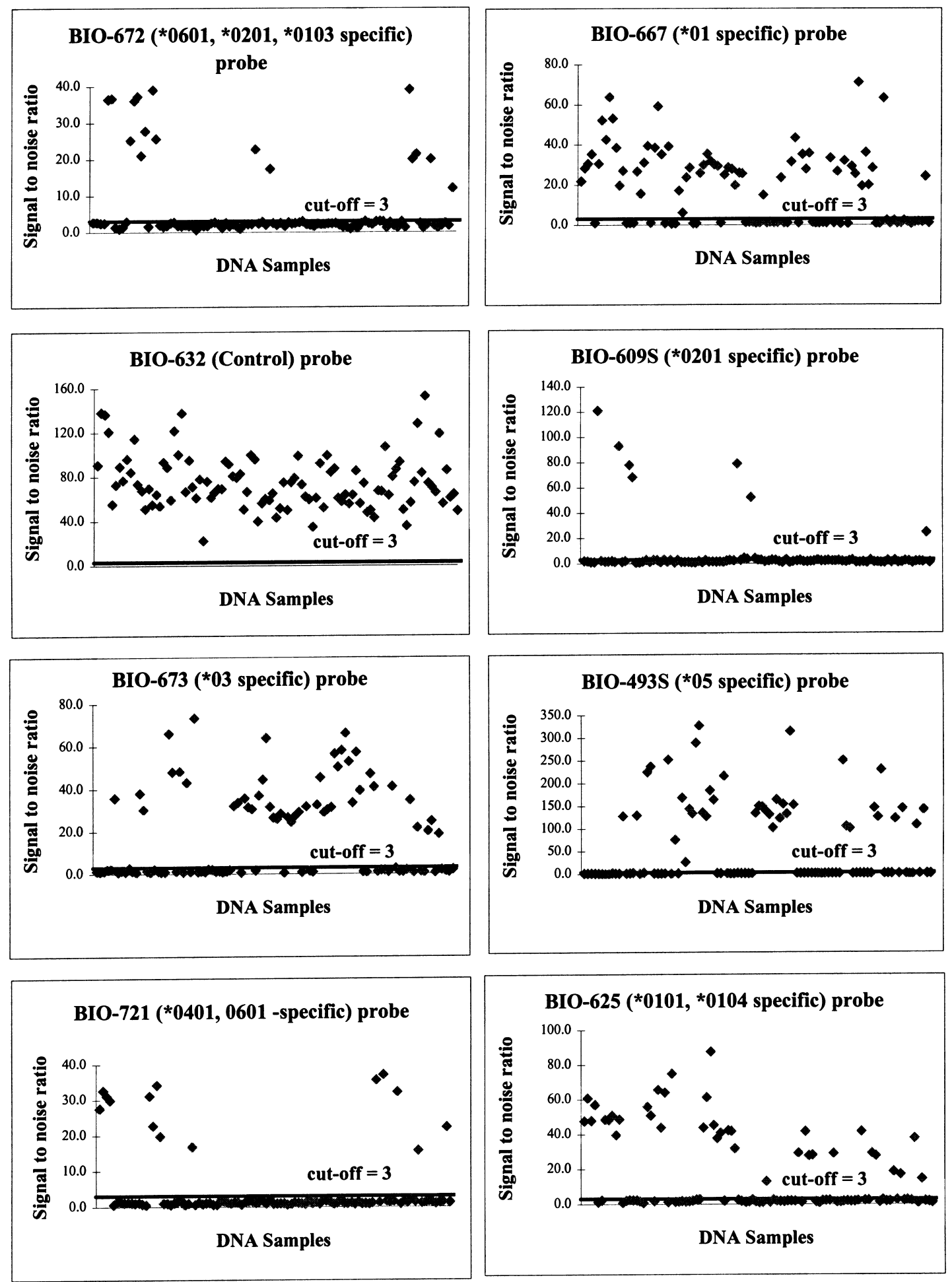

Fig. 2. Results of the study of 100 DNA samples determined with the HLA-DQA1 assay. No false results were found when the cut-off value was set at signal-to-noise ratio three. 
indicates a $100 \%$ specificity. It has to be emphasised that the specificity of our assay is increased not only because of the discrimination power of short oligoprobes but also because two probes specific for different parts of the target sequence are used in every hybridisation reaction.

The lowest, but still clearly detectable, S/N (6.1) was obtained with genomic DNA sample number 29 screened with Bio-667 probe. This sample also had the lowest S/N (22.2) with the control probe Bio-632, indicating a relatively poor amplification. On average the highest $\mathrm{S} / \mathrm{N}$ with DNA samples were found with the catching probe Bio-493S. This is largely due to the fact, that the longer the probe is the better the hybridisation efficiency. Probes with equal lengths (the specific sequence of Bio-493S is 13 bases long), i.e. Bio-494 and Bio-609S, as well as longer probes Bio-625, Bio-667 and Bio-673, did not reach the $\mathrm{S} / \mathrm{N}$ level of Bio-493S. To overcome cross-hybridisation, the washing temperatures for probes Bio-609S and Bio-625 had to be increased, which also decreased the specific Eu-signal, thus explaining the lower $\mathrm{S} / \mathrm{N}$ obtained. The lower $\mathrm{S} / \mathrm{N}$ level reached with the longer probe Bio-667 can be explained by the approximately two times higher background levels compared with those of all other Bioprobes. The equally low hybridisation signal obtained with Bio-673 can be at least partially explained by the extra spacer arm in Bio-493S, thus making the probe more flexible in solution hybridisation. The S/N levels of Bio-494 with authentic samples are not accessible, since no DQA1*0502 positive DNA was available, but according to the positive signals obtained with the synthetic target oligo to mimic PCR product, it can be assumed that the probe is feasible.

For the blood spots analysed, a uniform decrease in the $\mathrm{S} / \mathrm{N}$ with all probes was found when compared with those of isolated genomic DNA samples. This was mainly due to the lower amount of template DNA available and possible PCR inhibitors [19,21] in blood spots. The lowest positive S/N observed was 5.3 with sample number 14 , and the highest $\mathrm{S} / \mathrm{N}$ ratio was 89.0 with sample number 5. To help the interpretation of borderline positive or negative signals, a control probe (valuable especially with blood spot samples) is added to the probe panel to indicate a possible PCR failure. Another built-in control can be accomplished by screening each individual sample with all DQA1 probes, since at least two positive reactions per one sample should be found.

In practice, the detection sensitivities of our probes (Table 2) were found to be sufficient for detection, because DNA samples can be amplified to compensate for even low sensitivities. Generally, in TRF-based hybridisation assays the sensitivities of short probes have varied from $2 \times 10^{7}$ to $1 \times 10^{10}$ molecules [10,15,30], depending on the lanthanide label and the length of the probe used.

The assay is unable to distinguish DQA $1 * 0101$ from $* 0104, * 0301$ from $* 0302$ and $* 0501$ from *0503 allele. In addition, the heterozygous genotype *0101/0101 can not be discriminated from the hybridisation patterns of $* 0101 / 0102$, $* 0101 / 0104, * 0104 / 0104$ and *0102/0104. All other *01 heterozygous and homozygous combinations can be identified. The value of each discrimination is dependent on the purpose for which the assay is used. The usefulness of DQA typing for disease association studies is limited and the probes of informative value can be specifically selected in the described procedure. In practice, we are currently using a combination of DQA $1 * 05$ and $* 0201$ probes to study subjects earlier screened to be positive for DQB $1 * 02$ allele with the purpose to detect the presence of DQA1*0501-DQB1*0201 heterodimer confer-ring susceptibility to celiac disease and IDDM.

The microtitration plate format of our HLADQA1 typing assay with different DELFIA $^{\circledR}$ instruments supports automation. Thus the assay is time saving compared for example with laborious and error-prone, conventional serological DQA1 typing assays. In addition, numerical results (cps) enable easy data handling of our hybridisation probe patterns. 


\section{Acknowledgements}

The work was partly supported by a grant from the Academy of Finland. Ms Teija Ristelä is acknowledged for reviewing the manuscript.

\section{References}

[1] Allen, M., Saldeen, T. and Gyllensten, U. Allelespecific HLA-DRB1 amplification of forensic evidence samples with mixed genotypes. BioTechniques 19, (1995) 454-463.

[2] Bein, G., Haase, D., Schult, J., Eiermann, T. and Kirchner, H. Semiautomated HLA-DQB1 typing by fluorescent dye photometry of amplified DNA on microtiter plates. Hum. Immunol. 39, (1994) $1-8$.

[3] Bidwell, J. Advances in DNA-based HLA-typing methods. Immunol. Today 15, (1994) 303-307.

[4] Buyse, I., Decorte, R., Baens, M., Cuppens, H., Semana, G., Emonds, M.P., Marynen, P. and Cassiman, J.J. Rapid DNA typing of class II HLA antigens using the polymerase chain reaction and reverse dot blot hybridization. Tissue Antigens 41, (1993) 1-14.

[5] Chia, D., Terasaki, P., Chan, H., Acalinovich, A., Maruya, E., Saji, H. and Ware, K. A new simplified method of gene typing. Tissue Antigens 44, (1994) 300-305.

[6] Eskola, J., Hämäläinen, M., Näntö, V., Rajamäki, A., Dahlén, P., Iitiä, A. and Siitari, H. Detection of Philadelphia chromosome using PCR and europium-labeled DNA probes. Clin. Biochem. 27, (1994) 373-379.

[7] Faas, S.J., Menon, R., Braun, E.R., Rudert, W.A. and Trucco, M. Sequence-specific priming and exonuclease-released fluorescence detection of HLA-DQB1 alleles. Tissue Antigens 48, (1996) 97-112.

[8] Giorda, R., Lampasona, V., Kocova, M. and Trucco, M. Non-radioisotopic typing of human leukocyte antigen class II genes on microplates. BioTechniques 15, (1993) 918-925.

[9] Halonen, P., Rocha, E., Hierholzer, J., Holloway, B., Hyypiä, T., Hurskainen, P. and Pallansch, M. Detection of enteroviruses and rhinoviruses in clinical specimens by PCR and liquid-phase hybridization. J. Clin. Microbiol. 33, (1995) 648653.
[10] Heinonen, P., Iitiä, A., Torresani, T. and Lövgren, T. Simple triple-label detection of seven cystic fibrosis mutations employing timeresolved fluorometry. Clin. Chem. 43, (1997) 1142-1150.

[11] Hierholzer, J., Halonen, P., Dahlén, P., Bingham, $\mathrm{P}$. and McDonough, M. Detection of adenovirus in clinical specimens by polymerase chain reaction and liquid-phase hybridization quantitated by time-resolved fluorometry. J. Clin. Microbiol. 31, (1993) 1886-1891.

[12] Hurskainen, P., Dahlén, P., Ylikoski, J., Kwiatkowski, M., Siitari, H. and Lövgren, T. Preparation of europium-labelled DNA probes and their properties. Nucleic Acids. Res. 19, (1991) 1057-1061.

[13] Iitiä, A., Dahlén, P., Nunn, M., Mukkala, V.M. and Siitari, H. Detection of amplified HTLV-I /II viral sequences using time-resolved fluorometry. Anal. Biochem. 202, (1992) 76-81.

[14] Iitiä, A., Høgdall, E., Dahlén, P., Hurskainen, P., Vuust, J. and Siitari, H. Detection of mutation $\Delta F 508$ in the cystic fibrosis gene using allelespecific PCR primers and time-resolved fluorometry. PCR Methods Appl. 2, (1992) 157162.

[15] Iitiä, A., Liukkonen, L. and Siitari, H. Simultaneous detection of two cystic fibrosis alleles using dual-label time-resolved fluorometry. Mol. Cell. Probes 6, (1992) 505512.

[16] Iitiä, A., Mikola, M., Gregersen, N., Hurskainen, P. and Lövgren, T. Detection of point mutation using short oligonucleotide probes in allelespecific hybridization. BioTechniques 17, (1994) 566-573.

[17] Lövgren, T., Iitiä, A., Hurskainen, P. and Dahlén, P. Detection of lanthanide chelates by timeresolved fluorescence. In: Kricka, L. (ed.) Nonisotopic Probing, Blotting and Sequencing. San Diego: Academic Press, (1995) 331-390.

[18] Maeda, M., Murayama, N., Ishii, H., Uryu, N., Ota, M., Tsuji, K. and Inoko, H. A simple and rapid method for HLA-DQA1 genotyping by digestion of PCR-amplified DNA with allele specific restriction endonucleases. Tissue Antigens 34, (1989) 290-298.

[19] Makowski, G., Davis, E., Aslanzadeh, J. and Hopfer, S. Enhanced direct amplification of Guthrie card DNA following selective elution of PCR inhibitors. Nuceic Acids Res. 23, (1995) 3788-3789. 
[20] Marsh, S. and Bodmer, J. HLA class II region nucleotide sequences. Tissue Antigens 45, (1995) 258-280.

[21] Mercier, B., Gaucher, C., Feugeas, O. and Mazurier, C. Direct PCR from whole blood, without DNA extraction. Nucleic Acids Res. 18, (1990) 5908.

[22] Miller, S.A., Dykes, D.D. and Polesky, H.F. A simple salting out procedure for extracting DNA from human nucleated cells. Nucleic Acids Res. 16, (1988) 1215.

[23] Olerup, O. and Zetterquist, H. HLA-DR typing by PCR amplification with sequence-specific primers (PCR-SSP) in 2 hours: an alternative to serological DR typing in clinical practice including donor-recipient matching in cadaveric transplantation. Tissue Antigens 39, (1992) 225235.

[24] Olerup, O., Aldener, A. and Fogdell, A. HLADQB1 and -DQA1 typing by PCR amplification with sequence-specific primers (PCR-SSP) in 2 hours. Tissue Antigens 41, (1993) 119-134.

[25] Ota, M., Seki, T., Nomura, N., Sugimura, K., Mizuki, N., Fukushima, H., Tsuji, K. and Inoko, H. Modified PCR-RFLP method for HLA-DPB1 and -DQA1 genotyping. Tissue Antigens 38, (1991) 60-71.

[26] Pai, C.Y., Chou, S.L., Yang, C.H. and Tang, T. Flow chart of HLA-DQA1 genotyping and its application to a forensic case. J. Forensic Sci. 40, (1995) 228-235.
[27] Reijonen, H., Ilonen, J., Knip, M. and Åkerblom, H.K. HLA-DQB1 alleles and absence of asp57 as susceptibility factors of IDDM in Finland. Diabetes 40, (1991) 1640-1644.

[28] Saiki, R., Sean Walsh, P., Levenson, C. and Erlich, H. Genetic analysis of amplified DNA with immobilized sequence-specific oligonucleotide probes. Proc. Natl. Acad. Sci. USA, 86, (1989) 6230-6234.

[29] Santamaria, P., Boyce-Jacino, M., Lindstrom, A., Barbosa, J., Faras, A. and Rich, S. HLA class II "typing": direct sequencing of DRB, DQB and DQA genes. Hum. Immunol. 33, (1992) 69-81.

[30] Sjöroos, M., Iitiä, A., Ilonen, J., Reijonen, H. and Lövgren, T. Triple-label hybridization assay for type-1 diabetes-related HLA alleles. BioTechniques 18, (1995) 870-877.

[31] Soini, E. and Lövgren, T. Time-resolved fluorescence of lanthanide probes and applications in biotechnology. CRC Crit. Rev. Anal. Chem. 18, (1987) 105-154.

[32] Sund, C., Ylikoski, J., Hurskainen, P. and Kwiatkowski, M. Construction of europium $\left(\mathrm{Eu}^{3+}\right)$-labelled oligo DNA hybridization probes. Nucleosides \& Nucleotides 7, (1988) 655-659.

[33] Thein, S. and Wallace B. The use of synthetic oligonucleotides as specific hybridisation probes in the diagnosis of genetic disorders. In: Davis, K. (ed.) Human Genetic Diseases: A Practical Approach. Herndon, Virginia: IRL Press, (1986) 33-50. 


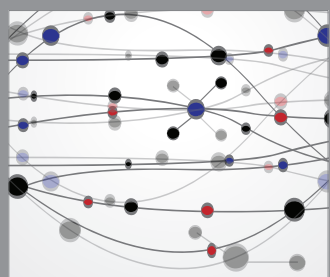

The Scientific World Journal
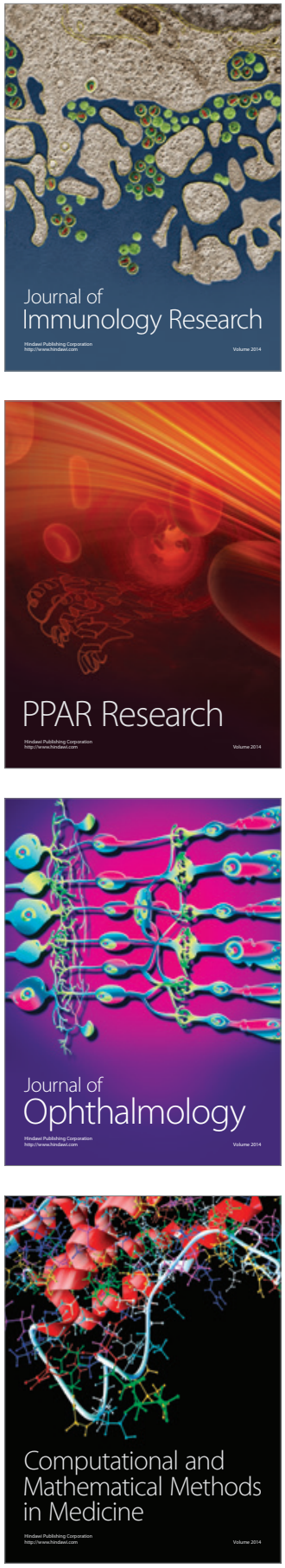

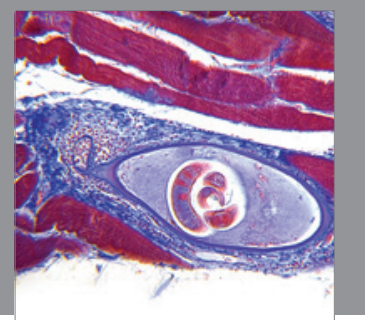

Gastroenterology

Research and Practice
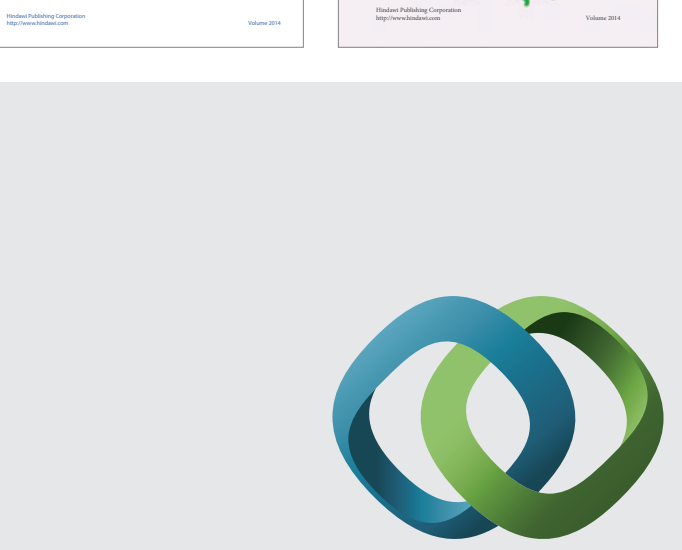

\section{Hindawi}

Submit your manuscripts at

http://www.hindawi.com
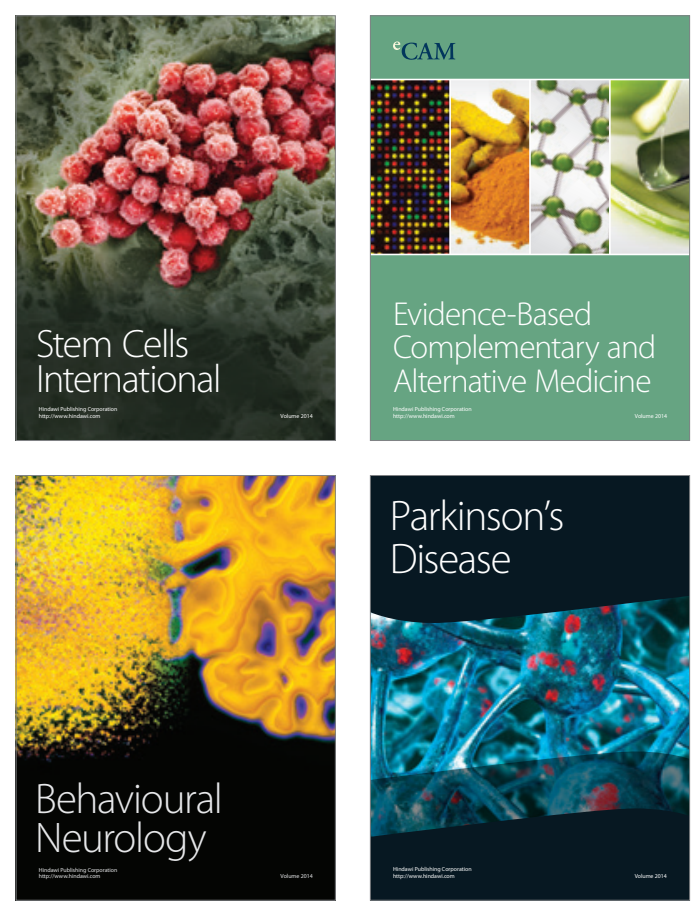

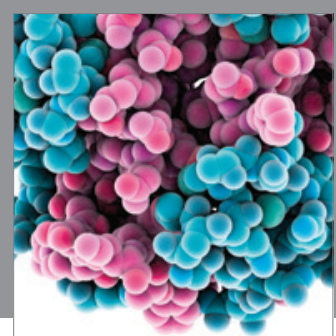

Journal of
Diabetes Research

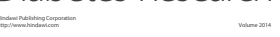

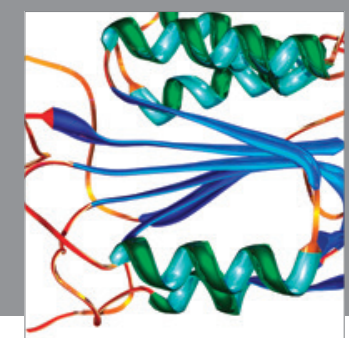

Disease Markers
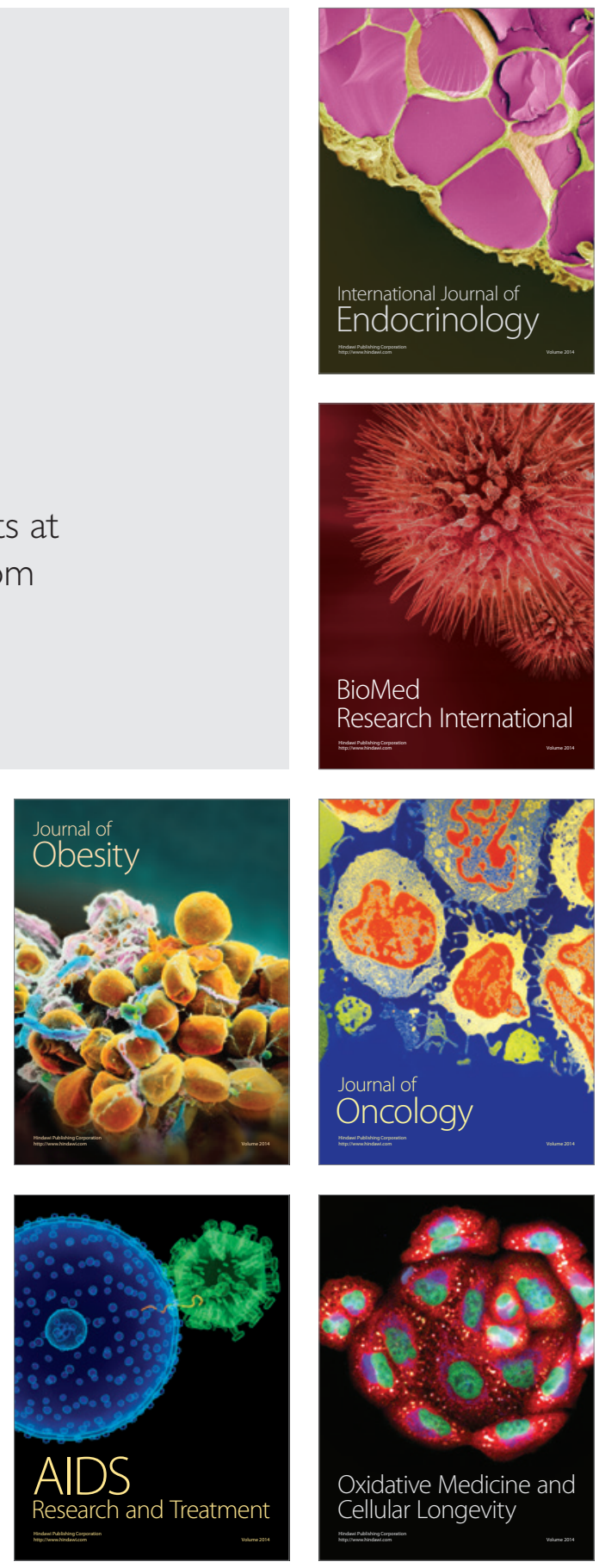